\title{
Review Article \\ Role of Nitrative and Oxidative DNA Damage in Inflammation-Related Carcinogenesis
}

\author{
Mariko Murata, ${ }^{1}$ Raynoo Thanan, ${ }^{1,2}$ Ning $\mathrm{Ma}^{3}{ }^{3}$ and Shosuke Kawanishi ${ }^{2}$ \\ ${ }^{1}$ Department of Environmental and Molecular Medicine, Mie University Graduate School of Medicine, Tsu, 514-8507, Japan \\ ${ }^{2}$ Faculty of Pharmaceutical Sciences, Suzuka University of Medical Science, Suzuka, 513-8670, Japan \\ ${ }^{3}$ Faculty of Health Science, Suzuka University of Medical Science, Suzuka, 510-0293, Japan
}

Correspondence should be addressed to Shosuke Kawanishi, kawanisi@suzuka-u.ac.jp

Received 28 July 2011; Accepted 7 October 2011

Academic Editor: Vassilis Gorgoulis

Copyright (C) 2012 Mariko Murata et al. This is an open access article distributed under the Creative Commons Attribution License, which permits unrestricted use, distribution, and reproduction in any medium, provided the original work is properly cited.

\begin{abstract}
Chronic inflammation induced by biological, chemical, and physical factors has been found to be associated with the increased risk of cancer in various organs. We revealed that infectious agents including liver fluke, Helicobacter pylori, and human papilloma virus and noninfectious agents such as asbestos fiber induced iNOS-dependent formation of 8-nitroguanine and 8oxo-7, 8-dihydro-2'-deoxyguanosine (8-oxodG) in cancer tissues and precancerous regions. Our results with the colocalization of phosphorylated ATM and $\gamma$-H2AX with 8-oxodG and 8-nitroguanine in inflammation-related cancer tissues suggest that DNA base damage leads to double-stranded breaks. It is interesting from the aspect of genetic instability. We also demonstrated IL-6-modulated iNOS expression via STAT3 and EGFR in Epstein-Barr-virus-associated nasopharyngeal carcinoma and found promoter hypermethylation in several tumor suppressor genes. Such epigenetic alteration may occur by controlling the DNA methylation through IL-6-mediated JAK/STAT3 pathways. Collectively, 8-nitroguanine would be a useful biomarker for predicting the risk of inflammation-related cancers.
\end{abstract}

\section{Introduction}

Chronic inflammation induced by biological, chemical, and physical factors has been found to be associated with the increased risk of cancer in various organs [1-3] (Table 1). Inflammation activates a variety of inflammatory cells, which trigger oxidant-generating enzymes such as inducible nitric oxide synthase (iNOS), NADPH oxidase, and myeloperoxidase to produce high concentrations of free radicals including reactive nitrogen species (RNS) and reactive oxygen species (ROS) [1]. Overproduction of RNS and ROS can change the balance of oxidants and antioxidants and cause nitrative and oxidative stress which contributes to the damage of biomolecules such as DNA, RNA, lipid and proteins, leading to an increase in mutations, genomic instability, epigenetic changes, and protein dysfunction and play roles in the multistage carcinogenic process.

ROS generate 8-oxo-7,8-dihydro-2' -deoxyguanosine (8oxodG, also known as 8-hydroxydG (8-OHdG)), a marker of oxidative DNA damage $[4,5]$. 8-OxodG, a potentially muta- genic DNA lesion, leading to the transversion of $\mathrm{G}: \mathrm{C}$ to $\mathrm{T}$ : A ( $\mathrm{G} \rightarrow \mathrm{T}$ transversion) [6], has been implicated in cancers triggered by infections [7]. The generation of ROS is not confined to inflammatory processes. Carcinogenic chemicals and their metabolites as well as electron transport chains in mitochondria are able to generate ROS. On the other hand, nitric oxide (NO), a primary initiator of RNS, is generated specifically during inflammation via iNOS in inflammatory and epithelial cells $[5,8]$. Overproduction of NO participates in the generation of peroxynitrite $\left(\mathrm{ONOO}^{-}\right)$, which can lead to the formation of 8-nitroguanine, an indicator of nitrative DNA damage $[9,10]$. 8-Nitroguanine undergoes spontaneous depurination in DNA, resulting in the formation of an apurinic site [11]. Incorporated adenine can form a pair with apurinic sites during DNA replication, leading to the $\mathrm{G} \rightarrow \mathrm{T}$ transversion [12] (Figure 1). Moreover, apurinic sites might represent major damage that requires error-prone DNA polymerase $\zeta$ for efficient trans-lesion DNA synthesis. It was reported that DNA polymerase $\zeta$ can efficiently bypass abasic sites by extending from nucleotides 


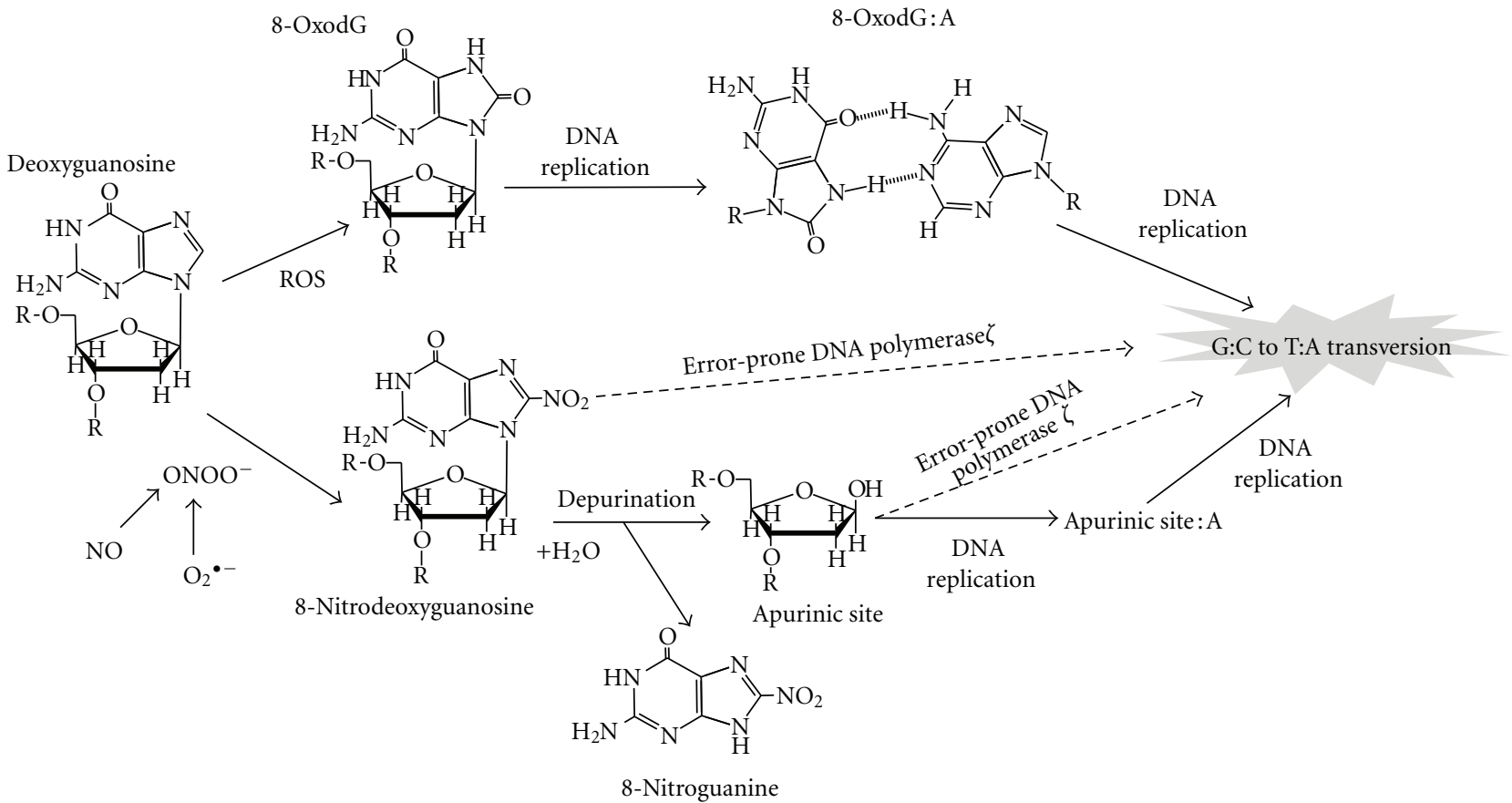

FIgure 1: Proposed mechanism of point mutation induced by 8-nitroguanine and 8-oxodG through induction of the G: C $\rightarrow$ T:A transversion.

TABLE 1: Nitrative and oxidative DNA damage in inflammation-induced carcinogenesis.

\begin{tabular}{|c|c|c|c|c|}
\hline $\begin{array}{l}\text { Etiologic agent/pathologic } \\
\text { condition }\end{array}$ & $\begin{array}{c}\text { IARC } \\
\text { classification }\end{array}$ & Cancer site & Associated neoplasm & $\begin{array}{l}\text { Detection of DNA } \\
\text { lesions }^{c} \text { [reference no.] }\end{array}$ \\
\hline \multicolumn{5}{|l|}{ (I) Infection agent } \\
\hline \multicolumn{5}{|l|}{ Viruses } \\
\hline \multicolumn{5}{|l|}{$\mathrm{HPV}^{\mathrm{b}}$} \\
\hline High-risk types & 1 & \multirow{2}{*}{ Cervix and other site } & \multirow{2}{*}{ Cervical carcinoma } & \multirow{2}{*}{ IHC [38] } \\
\hline Low-risk types & $2 \mathrm{~A}$ & & & \\
\hline $\mathrm{HCV}, \mathrm{HBV}^{\mathrm{b}}$ & 1 & Liver & Hepatocellular carcinoma & IHC [56-59] \\
\hline $\mathrm{EBV}^{\mathrm{b}}$ & 1 & Nasopharynx & Nasopharyngeal carcinoma & $\begin{array}{l}\text { IHC }[38,49,50], \\
\text { ELISA [49] }\end{array}$ \\
\hline \multicolumn{5}{|l|}{ Bacterium } \\
\hline Helicobacter pylori & 1 & Stomach & Gastric cancer & IHC [36] \\
\hline \multicolumn{5}{|l|}{ Parasites } \\
\hline Opisthorchis viverrini & 1 & Intra- and extrahepatic bile duct & Cholangiocarcinoma & $\begin{array}{l}\text { IHC [17, 22-26], } \\
\text { HPLC-ECD [23, 27] }\end{array}$ \\
\hline Schistosoma haematobium & 1 & Bladder & Bladder cancer & IHC [60] \\
\hline \multicolumn{5}{|l|}{ (II) Inflammatory disease } \\
\hline Asbestos fiber & 1 & Lung & Mesothelioma, lung carcinoma & $\mathrm{IHC}[61]$ \\
\hline $\begin{array}{l}\text { Reflux oesophagitis Barrett's } \\
\text { oesophagitis }\end{array}$ & & Oesophagus & Oesophageal carcinoma & IHC (In prep.) \\
\hline Lichen planus & & Oral & Oral squamous cell carcinoma & IHC [62] \\
\hline Inflammatory bowel disease & & Colon & Colorectal carcinoma & $\mathrm{IHC}[63]$ \\
\hline \multicolumn{5}{|l|}{ Crohn's disease } \\
\hline Chronic ulcerative colitis & & & & IHC (this paper) \\
\hline Unknown & & Soft tissue & Malignant fibrous histiocytoma & IHC $[64,65]$ \\
\hline
\end{tabular}

This table was adapted and modified from the IARC [2] and Coussens and Werb [1].

IARC: International Agency for Research on Cancer. ${ }^{2}$ IARC classification: Group 1: carcinogenic to humans; Group 2A: probably carcinogenic to humans.

${ }^{b} \mathrm{HPV}$ : human papilloma virus; HBV: hepatitis B virus; HCV: hepatitis C virus; EBV: Epstein-Barr virus.

${ }^{\mathrm{c}}$ DNA lesions: IHC, 8-nitroguanine and 8-oxodG detected by immunohistochemistry; HPLC-ECD: 8-oxodG detected by HPLC-ECD; ELISA: serum 8-oxodG detected by ELISA. 
inserted opposite the lesion by other DNA polymerases [13]. $\mathrm{Wu}$ et al. suggested that cells deficient in subunits of DNA polymerase $\zeta$ were hypersensitive to nitrative stress, and trans-lesion DNA synthesis mediated by this polymerase contributes to extensive point mutations [14]. Additionally, DNA polymerases $\eta$ and $\kappa$ were also found to be involved in the incorporation of adenine opposite 8-nitroguanine during DNA synthesis in a cell-free system associated with translesion DNA synthesis leading to the $\mathrm{G} \rightarrow \mathrm{T}$ transversion [15]. Therefore, 8-nitroguanine is a potential mutagenic DNA lesion involved in inflammation-mediated carcinogenesis. Relevantly, systematic and comprehensive genomescale approaches by using the immunoprecipitation-based technique combined with high-density microarrays may be useful to investigate roles of DNA lesions in carcinogenesis [16].

We focus on the roles of nitrative and oxidative DNA damage in infection- and inflammation-related carcinogenesis. We produced a specific anti-8-nitroguanine antibody [17] and examined the localization of DNA lesions by immunohistochemical analysis in animal models and clinical samples (Table 1). Here, we review the effects of RNS/ROS-mediated DNA damage on genomic instability and epigenetic change in relation to carcinogenesis.

\section{DNA Damage in Infection-Related Carcinogenesis}

2.1. Liver Fluke Infection and Cholangiocarcinoma. Liver fluke infections of Opisthorchis viverrini (O. viverrini) are a risk factor for cholangiocarcinoma in Southeast Asia [18]. O. viverrini infestations are endemic in Khon Kaen province, northeastern Thailand, and Khon Kaen has the highest incidence of cholangiocarcinoma in the world [19]. O. viverrini infections induce inflammation in both animal models [20] and humans [21]. Our previous studies showed that 8-oxodG and 8-nitroguanine levels were increased in $O$. viverrini-infected hamsters compared with uninfected control groups [17, 22-24]. In addition, DNA damage was significantly increased in reinfected hamsters compared with animals infected just once [23]. Notably, repeated infection increased iNOS expression and 8-nitroguanine production in the epithelium of bile ducts even after a decrease in inflammatory cells. To elucidate the mechanism involved, we examined the expression of iNOS, NF- $\kappa \mathrm{B}$, and Toll-like receptor (TLR) 2 in mouse macrophage cell lines treated with $O$. viverrini crude antigens [25], suggesting that $O$. viverrini infection induced TLR2 activation with NF- $\kappa \mathrm{B}$-dependent transcription and iNOS expression. Treatment with an antiparasitic drug (praziquantel) significantly improved the DNA lesions [22]. These findings in hamsters were confirmed by the observation that 8-oxodG and 8-nitroguanine accumulated more in cancerous areas than in intrahepatic areas adjacent to tumors in surgical specimens [26]. Furthermore, an epidemiological study of O. viverrini-infected subjects and cholangiocarcinoma patients demonstrated that urinary 8-oxodG levels were significantly higher in cholangiocarcinoma patients than in O. viverrini-infected patients and healthy subjects and higher in O. viverrini-infected subjects than in healthy subjects [27]. The urinary 8-oxodG levels in O. viverrini-infected patients significantly decreased two months after praziquantel treatment and were comparable to levels in healthy subjects one year after treatment [27]. These results indicate that $O$. viverrini causes chronic and recurrent inflammation followed by the accumulation of oxidative and nitrative DNA lesions, which may participate in the development of cholangiocarcinomas.

2.2. H. pylori and Gastric Cancer. Helicobacter pylori is the main cause of chronic gastritis and a potential risk factor for gastric carcinoma [28]. The molecular mechanisms behind $H$. pylori-induced production of ROS/RNS were wide ranging from activated neutrophils to $H$. pylori itself, as nicely reviewed by Handa et al. [29]. H. pylori infections promote the secretion of various inflammatory cytokines, contributing directly to the pronounced inflammatory response. Lipopolysaccharide, a component of Gram-negative bacteria such as H. pylori, is a TLR4 ligand that induces inflammatory responses via NF- $\kappa \mathrm{B}$ expression [30]. NF- $\kappa \mathrm{B}$, which is involved in the regulation of iNOS, had been reported to function as a tumor promoter in inflammation-associated cancer $[31,32]$. In patients with $H$. pylori-induced gastritis or gastric ulcers, iNOS is expressed in the infiltrating inflammatory cells [33]. The expression of iNOS mRNA and protein was significantly increased in the epithelial cells of $H$. pylori-positive gastritis patients compared to $H$. pylorinegative patients [34]. Recently, it was also found that $H$. pylori in a Korean isolate induced the expression of iNOS via AP-1 activation [35]. Our previous study [36] demonstrated that levels of 8-nitroguanine and 8-oxodG in gastric gland epithelium were significantly higher in gastritis patients with H. pylori infections than in those without infections. A significant accumulation of proliferating cell nuclear antigen (PCNA) was observed in gastric gland epithelial cells in patients infected with $H$. pylori in comparison to those not infected. Interestingly, the accumulation of PCNA was closely correlated with the formation of 8-nitroguanine and 8-oxodG. Collectively, the host response to $H$. pylori mediated NF- $\kappa$ B expression, resulting in iNOS expression accompanied by 8 -nitroguanine and 8-oxodG production in the gastric epithelium. 8-Nitroguanine could be not only a promising biomarker for inflammation but also a useful indicator of the risk of developing gastric cancer in response to chronic $H$. pylori infection.

2.3. HPV and Cervical Carcinoma. Cervical cancer is the second most common cancer among women worldwide and the most common cancer among women in many developing countries [37]. Inflammation is proposed to play an integral role in the development of human papilloma virus (HPV)induced cervical cancer [1]. Our previous study [38] examined the formation of 8-nitroguanine and 8-oxodG in cells of cervical intraepithelial neoplasia (CIN, grades 1-3) and condyloma acuminatum samples and compared it with the expression of the cyclin-dependent kinase inhibitor p16, considered a biomarker for cervical neoplasia [39-42]. Double immunofluorescence labeling revealed that 8-nitroguanine and 8-oxodG immunoreactivities correlated significantly 
with CIN grade. There were no statistically significant differences in p16 expression between CIN and condyloma acuminatum samples. These results suggest that high-risk HPV types promote iNOS-dependent DNA damage, which leads to dysplastic changes and carcinogenesis. Therefore, 8nitroguanine is a more suitable and promising biomarker for evaluating the risk of inflammation-mediated cervical carcinogenesis than $\mathrm{p} 16$.

2.4. EBV and Nasopharyngeal Carcinoma. Nasopharyngeal carcinoma (NPC) is strongly associated with Epstein-Barr virus (EBV) infections [43]. Various transcription factors are known to participate in iNOS expression including signal transducers and activators of transcription (STATs), such as STAT $1 \alpha$ and STAT3 $[44,45]$. Epidermal growth factor receptor (EGFR) physically interacts with STAT3 in the nucleus, leading to transcriptional activation of iNOS [44]. STAT3 is repeatedly activated through phosphorylation via the expression of latent membrane protein 1 (LMP1) as well as EGFR [46, 47], and interleukin-6 (IL-6) is required for LMP1-mediated STAT3 activation [46]. In addition, LMP1-mediated iNOS expression was reported in EBV-infected epithelium cell lines, which play a role in colonization independent of anchorage and tumorigenicity in nude mice [48]. Using biopsy and surgical specimens of nasopharyngeal tissues from NPC patients in southern China, we performed double immunofluorescent staining to examine the formation of 8-nitroguanine and 8-oxodG $[49,50]$. Intensive immunoreactivity to iNOS was detected in the cytoplasm of 8-nitroguanine-positive cancer cells. DNA lesions and iNOS expression were also observed in epithelial cells of EBV-positive patients with chronic nasopharyngitis but weaker than those in NPC patients. No or few DNA lesions were observed in EBV-negative subjects. EGFR and phosphorylated STAT3 were strongly expressed in cancer cells of NPC patients, suggesting that the STAT3-dependent mechanism is important to the carcinogenesis [50]. IL-6 was expressed mainly in inflammatory cells of nasopharyngeal tissues of EBV-infected patients. We also found that serum levels of 8-oxodG were significantly higher in NPC patients than control subjects [49]. Collectively, these findings indicate that the nuclear accumulation of EGFR and activation of STAT3 by IL-6 play a key role in iNOS expression and resultant DNA damage, leading to EBV-related NPC.

2.5. HCV and Hepatocellular Carcinoma. Hepatitis C virus (HCV) is a major cause of chronic hepatitis, liver cirrhosis, and hepatocellular carcinoma throughout the world [51]. Hepatocellular carcinoma arises through genetic alterations in hepatocytes during a chronic HCV infection [52-55]. We investigated the extent of nucleic acid damage in HCVinfected individuals and its change after interferon treatment [56]. Immunoreactivities of 8-nitroguanine and 8-oxodG were strongly detected in the liver of patients with chronic hepatitis $\mathrm{C}$, but not control subjects. 8-Nitroguanine was found to be accumulated in hepatocytes particularly in the periportal area. In the sustained virological responder group after interferon therapy, the accumulation of 8nitroguanine and 8-oxodG was markedly decreased in the liver. We observed a strong correlation between hepatic 8oxodG staining and serum ferritin levels, suggesting the iron content to be a strong mediator of oxidative stress and iron reduction to reduce the incidence of hepatocellular carcinoma in patients with chronic hepatitis $C[57,58]$. We also demonstrated that oxidative DNA damage widely occurred in the livers of patients with chronic viral hepatitis especially chronic hepatitis $\mathrm{C}$, and the iron load and 8-oxodG-positive hepatocytic count was significantly higher in HCV-infected than in HBV-infected livers [59]. It is plausible that ROS production during chronic HCV infection is the result of high iron levels in hepatic tissues, which lead to progressive liver inflammation and an increased risk of developing liver cancer. These findings indicate that 8-nitroguanine and 8oxodG are useful as biomarkers for evaluating the severity of HCV-induced chronic inflammation leading to hepatocellular carcinoma and the efficacy of chronic hepatitis C treatment.

\section{DNA Damage in Inflammation-Related Carcinogenesis}

3.1. Asbestos and Lung Carcinoma. Excessive and persistent production of ROS/RNS by inflammatory cells is considered as a hallmark of the secondary genotoxicity of nonfibrous and fibrous particles including asbestos [66]. Asbestos is a carcinogen (IARC Group1) causing lung cancer and malignant mesothelioma of the pleura and peritoneum [67]. Among the different types of asbestos, crocidolite (blue asbestos) and amosite (brown asbestos) are more potent carcinogens than chrysotile (white asbestos) [67]. Inflammation is a hallmark of the response to exposure to asbestos in both animal and human models $[68,69]$. NO and nitrative stress were reported to be involved in the asbestos-derived inflammatory response via myeloperoxidase, a major constituent of neutrophils which generates hypochlorous acid and RNS [70-73]. Myeloperoxidase plays a significant role in asbestos-induced carcinogenesis [74]. However, the precise mechanisms of nitrative DNA damage remain to be clarified. We performed an immunohistochemical analysis to examine the formation of 8-nitroguanine and the expression of iNOS and its transcription factor (NF- $\kappa \mathrm{B})$ in the lungs of mice intratracheally administered asbestos fibers, including crocidolite and chrysolite [61]. 8-Nitroguanine was significantly detected in bronchial epithelial cells of asbestos-exposed groups compared with the untreated group. Interestingly, the immunoreactivities of 8-nitroguanine, iNOS, and NF$\kappa \mathrm{B}$ were significantly higher in the crocidolite-exposed group than in the chrysotile-exposed group. Therefore, the formation of nitrative DNA damage could be one of the mechanisms responsible for the difference in carcinogenic potential between crocidolite and chrysotile.

3.2. Inflammatory Bowel Disease and Colon Cancer. Ulcerative colitis and Crohn's disease, which are referred to as inflammatory bowel diseases (IBDs), are well known as chronic inflammatory diseases in the lower bowel. Epidemiological studies have shown that the incidence of colorectal cancer in IBD patients is greater than the expected incidence 


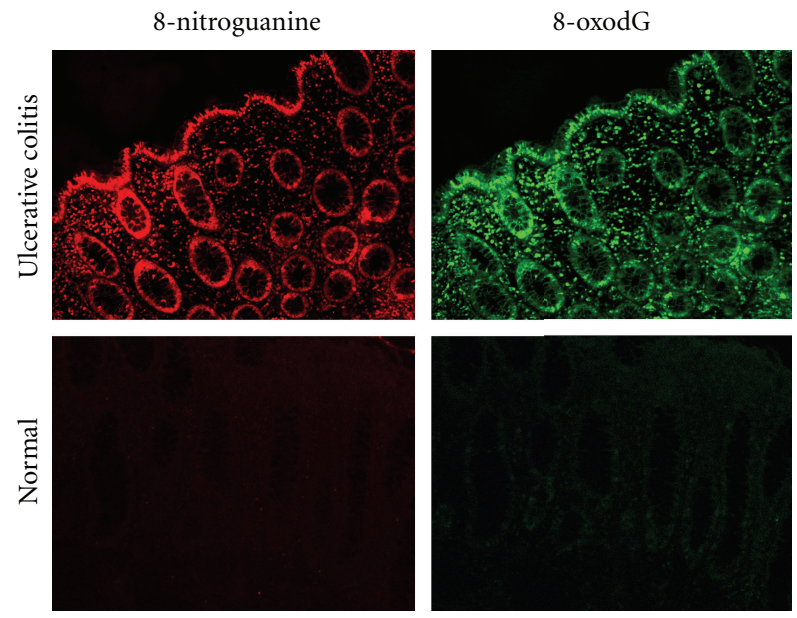

FIGURE 2: 8-Nitroguanine in colon epithelium of a patient with active ulcerative colitis.

in the general population [75]. We hypothesized that an imbalance of helper and regulatory $\mathrm{T}$-cell functions plays a key role in the pathogenesis of IBD. Therefore, we prepared a mouse model of IBD with an imbalance of Th1 and Th2 and, using double immunofluorescence labeling, revealed that both 8-nitroguanine and 8-oxodG were mainly formed in epithelial cells [63]. iNOS, PCNA, and p53 proteins were also expressed in colon epithelium. We observed by using clinical samples that 8-nitroguanine and 8-oxodG were formed in colon epithelium of patients with ulcerative colitis in the active stage (Figure 2). Of relevance, several studies have shown that iNOS is expressed in epithelial cells in colitis patients [76-78]. In noncancerous colon tissues from patients with ulcerative colitis, iNOS protein levels were positively correlated with p53 serine 15 phosphorylation levels [76]. These results suggest that nitrative DNA damage, as well as oxidative DNA damage, participates in colon carcinogenesis in patients with IBD.

3.3. Oral Lichen Planus and Oral Cancer. Oral lichen planus (OLP) is a chronic inflammatory mucosal disease [79] and a risk factor for oral squamous cell carcinoma (OSCC) [80]. Oral leukoplakia is a precancerous lesion characterized by white plaques and hyperkeratosis $[81,82]$. We demonstrated that 8-nitroguanine and 8-oxodG accumulated in oral epithelium of biopsy specimens from patients with OLP, leukoplakia, and OSCC, whereas no immunoreactivity was observed in normal oral mucosa $[62,83]$. Colocalization of 8-nitroguanine and iNOS was found in oral epithelium of patients with OLP, leukoplakia, and OSCC. Accumulation of p53 was observed in oral epithelium in OLP and leukoplakia patients, and more prominent expression of this protein was observed in OSCC patients. In addition, the immunoreactivity to PCNA was significantly higher in leukoplakia patients than that in normal mucosa, suggesting an increase in cell proliferation [83]. Lee et al. also reported that PCNA and p53 were highly expressed in oral tissues in OLP patients [84]. We conclude that inflammation-mediated DNA damage and additional epithelial cell proliferation promote oral carcinogenesis.
3.4. DNA Damage in Malignant Fibrous Histiocytoma. Malignant fibrous histiocytoma (MFH) is one of the most common soft tissue sarcomas $[85,86]$ and has a poor prognosis $[87,88]$. MFH has been proposed to be accompanied by inflammatory responses $[89,90]$. However, the mechanism of its inflammation-induced carcinogenesis is still unclear. We investigated DNA lesions and inflammatoryrelated molecules including iNOS, NF- $\kappa \mathrm{B}$, and COX-2 [64]. Immunohistochemical staining revealed that the formation of 8-nitroguanine and 8-oxodG occurred to a much greater extent in MFH tissue specimens from deceased patients than in live patients. iNOS, NF- $\kappa \mathrm{B}$, and COX-2 were colocalized with 8-nitroguanine in $\mathrm{MFH}$ tissues. It is worth noting that a statistical analysis using the Kaplan-Meier method demonstrated strong 8-nitroguanine staining to be associated with a poor prognosis. Furthermore, our study demonstrated significantly higher levels of both 8-nitroguanine and HIF$1 \alpha$ in the tissue specimens of deceased patients than in those of living subjects. Survival curves analyzed by the KaplanMeier method differed significantly between the groups with high and low staining of 8-nitroguanine as well as HIF- $1 \alpha$ [65]. These results suggest a significant role for the iNOSdependent formation of 8-nitroguanine via HIF- $1 \alpha$ and NF$\kappa \mathrm{B}$ in the progression of inflammation-related cancer. These results indicate that 8-nitroguanine is involved in not only the initiation of carcinogenesis but also its progression and prognosis in cases of MFH.

\section{DNA Damage in relation to Genomic Instability}

Genomic instability is a defining characteristic of most carcinogenesis through the accumulation of mutations in several tumor suppressor genes, oncogenes, and genes that are involved in maintaining genomic stability [91]. Events resulting in chromosomal instability, such as amplification and deletions of large segments of DNA, reciprocal and nonreciprocal translocations, aneuploidy, and polyploidy, constitute the large-scale genomic aberrations that characterize the majority of human cancer cells and are thought to accelerate 

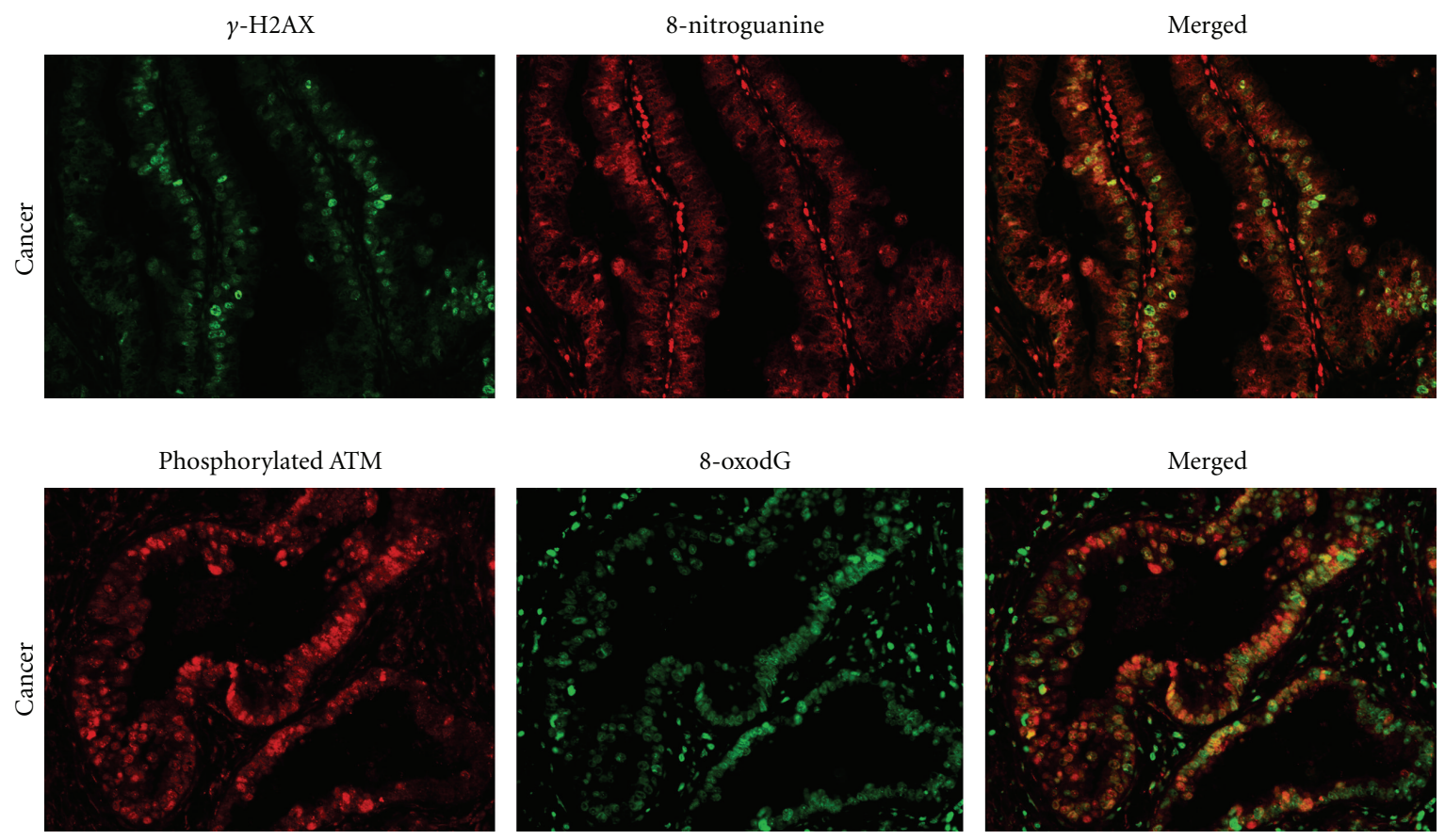

FIGURE 3: Colocalization of DDR proteins and DNA lesions. (a) Colocalization of $\gamma$-H2AX (green) and 8-nitroguanine (red). (b) Colocalization of phosphorylated ATM (green) and 8-oxodG (red).

carcinogenesis [91, 92]. Degtyareva et al. demonstrated that chronic oxidative DNA damage due to DNA repair defects induced chromosome instability in a Saccharomyces cerevisiae model [92]. Trouiller et al. showed that titanium dioxide, a risk factor for lung cancer, induced oxidative DNA damage, $\gamma$-H2AX foci, micronuclei, and DNA deletions, suggesting a link between inflammation-associated DNA damage and genomic instability [93]. The DNA damage response (DDR) is essential for maintaining the integrity of the genome, and a failure of this response results in genomic instability and predisposition to malignancy [94]. Phosphorylated ATM (ataxia telangiectasia mutated) plays a role in DDR to DNA double-stranded breaks. Impaired function of ATM was reported to be involved in DNA damage-induced genomic instability [94, 95]. TNF- $\alpha$ is a proinflammatory cytokine and also acts as an iNOS regulator protein $[96,97]$. Natarajan et al. reported that TNF- $\alpha$ induced the formation of 8-oxodG and genomic instability in primary vascular endothelial cells [98]. Yan et al. showed that antioxidants significantly reduced TNF- $\alpha$-induced genetic damage [99]. Therefore, TNF- $\alpha$ and a dysfunction of ATM could play key roles in the integration between iNOSmediated DNA damage and genomic instability. Recently, we observed that phosphorylated ATM and $\gamma$-H2AX were colocalized with 8-oxodG and 8-nitroguanine in clinical samples of cholangiocarcinoma patients as shown in Figure 3, suggesting that DNA base damage caused doublestranded breaks. DNA lesions were found in infiltrating inflammatory cells, hepatocyte cells of nontumor areas, and cancer cells, whereas $\gamma$-H2AX and phosphorylated ATM were expressed in only cancer cells. Moreover, DDR proteins and
DNA lesions were detected only very weakly in normal liver tissues, suggesting that the DNA double-stranded breaks were specific to cancer cells. Our observations also support the idea that highly iNOS-dependent DNA damage causes DNA double-stranded breaks and genomic instability, which play important roles in inflammation-induced carcinogenesis via TNF- $\alpha$ signaling and DDR protein dysfunction.

\section{DNA Damage in relation to Epigenetic Change}

Diverse cellular functions including the regulation of inflammatory gene expression, DNA repair, and cell proliferation are regulated by epigenetic changes [100]. DNA methylation and histone modifications are the major events involved in epigenetic changes. An important proinflammatory cytokine IL- 6 has been reported to control DNA methylation through IL-6-mediated Janus kinase (JAK)/STAT3 pathways [101105]. We demonstrated that IL-6 modulated iNOS expression via STAT3 and EGFR in EBV-associated nasopharyngeal carcinoma [50]. Accumulating evidence makes it increasingly clear that epigenetic silencing plays an important role in EBV-associated neoplasia [106]. We and our colleagues have found promoter hypermethylation in several candidate genes for tumor suppressor genes [107-110]. Histone modifications play a role in the response to DNA double-stranded breaks through ATM signaling to activate $\gamma$-H2AX, resulting in histone ubiquitination and acetylation, and destabilization and conformational changes to nucleosomes lead to DNA repair [111]. RNS cause base lesions, abasic sites, and singlestranded breaks, which may be converted into double-strand 


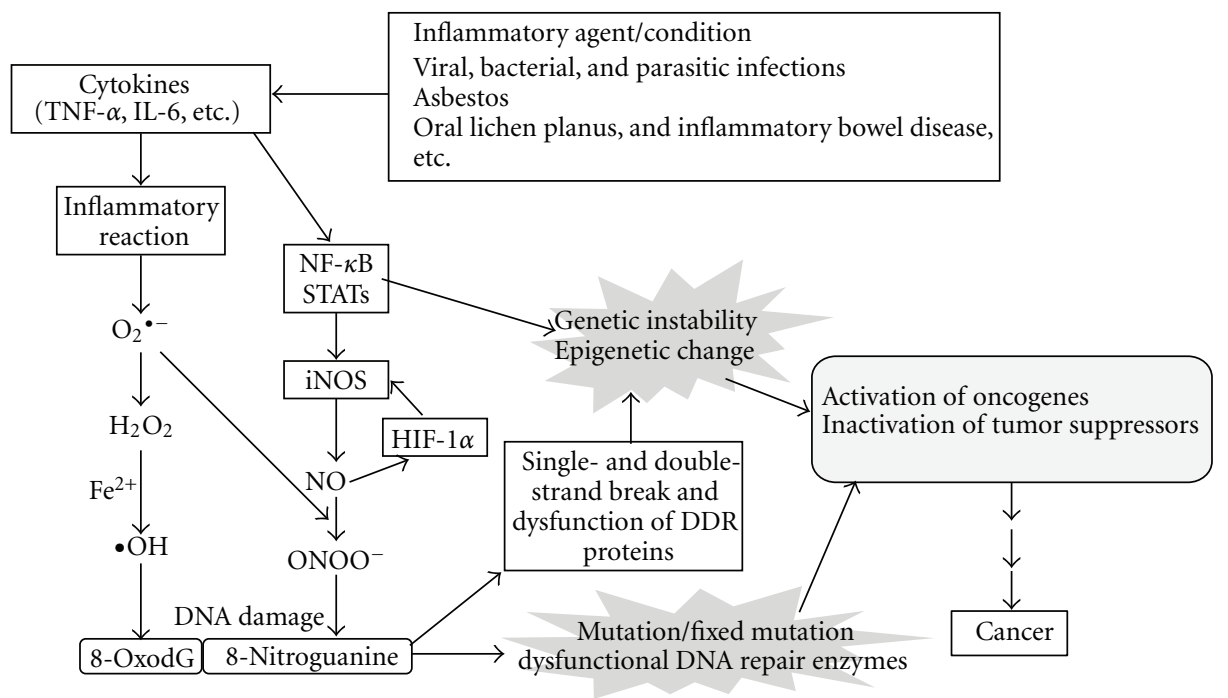

FIGURE 4: Proposed roles of nitrative and oxidative DNA damage in inflammation-related carcinogenesis.

breaks in cells by enzymatic processing, when the damage is in close proximity to or encountered by the replication fork [112]. Collectively, nitrative and oxidative DNA damage may activate epigenetic change via IL-6 signaling and the expression of DDR proteins.

\section{Conclusion}

We investigated the formation of 8-nitroguanine and 8oxodG at sites of carcinogenesis in various clinical specimens and animal models in relation to inflammation-related carcinogenesis. We also observed that DNA lesions were formed and significantly increased in S. haematobiuminduced urinary bladder cancer compared with cancer without such an infection [60]. In addition, Barrett's esophagus, an inflammation-related disease caused by the reflux of gastric acid, also showed greater DNA damage than normal esophageal tissues (unpublished data). Proposed roles of inflammation-related DNA damage in carcinogenesis on the basis of our findings and studies in the literature $[94,113]$ are summarized in Figure 4. 8-Nitroguanine and 8-oxodG are formed in various inflammation-related cancers and precancerous regions in an iNOS-dependent manner. TNF- $\alpha$ and IL- 6 are proinflammatory cytokines which play roles in the control of iNOS expression via the regulation of NF- $\kappa \mathrm{B}$ and STAT3 signaling pathways. 8-Nitroguanine and 8-oxodG are mutagenic lesions resulting in the $\mathrm{G} \rightarrow \mathrm{T}$ transversion. This type of mutation has been found to occur in vivo in the ras gene and the p53 tumor suppressor gene in various cancers [114]. Nitrative and oxidative DNA damage induce not only mutations but also genomic instability and epigenetic change via TNF- $\alpha$ and IL- 6 activities and DNA double-stranded breaks resulting in the activation of oncogenes and inactivation of tumor suppressor genes, which may lead to inflammation-related carcinogenesis.

\section{Acknowledgment}

The authors thank all coworkers at the Mie University Graduate School of Medicine (Japan), Khon Kaen University (Thailand), and Guangxi Medical University (China).

\section{References}

[1] L. M. Coussens and Z. Werb, "Inflammation and cancer," $N a-$ ture, vol. 420, no. 6917, pp. 860-867, 2002.

[2] IARC, "Chronic infections," in World Cancer Report, B. W. Stewart and P. Kleihues, Eds., pp. 56-61, IARC Press, Lyon, France, 2003.

[3] S. Kawanishi and Y. Hiraku, "Oxidative and nitrative DNA damage as biomarker for carcinogenesis with special reference to inflammation," Antioxidants and Redox Signaling, vol. 8, no. 5-6, pp. 1047-1058, 2006.

[4] S. Kawanishi, Y. Hiraku, and S. Oikawa, "Mechanism of guanine-specific DNA damage by oxidative stress and its role in carcinogenesis and aging," Mutation Research, vol. 488, no. 1, pp. 65-76, 2001.

[5] H. Ohshima, M. Tatemichi, and T. Sawa, "Chemical basis of inflammation-induced carcinogenesis," Archives of Biochemistry and Biophysics, vol. 417, no. 1, pp. 3-11, 2003.

[6] S. D. Bruner, D. P. G. Norman, and G. L. Verdine, "Structural basis for recognition and repair of the endogenous mutagen 8-oxoguanine in DNA," Nature, vol. 403, no. 6772, pp. 859$866,2000$.

[7] F. Farinati, R. Cardin, P. Degan et al., "Oxidative DNA damage in circulating leukocytes occurs as an early event in chronic HCV infection," Free Radical Biology and Medicine, vol. 27, no. 11-12, pp. 1284-1291, 1999.

[8] T. Akaike, S. Fujii, A. Kato et al., "Viral mutation accelerated by nitric oxide production during infection in vivo," The FASEB Journal, vol. 14, no. 10, pp. 1447-1454, 2000.

[9] B. Halliwell, "Oxygen and nitrogen are pro-carcinogens. Damage to DNA by reactive oxygen, chlorine and nitrogen species: measurement, mechanism and the effects of nutrition," Mutation Research, vol. 443, no. 1-2, pp. 37-52, 1999. 
[10] V. Yermilov, J. Rubio, M. Becchi, M. D. Friesen, B. Pignatelli, and H. Ohshima, "Formation of 8-nitroguanine by the reaction of guanine with peroxynitrite in vitro," Carcinogenesis, vol. 16, no. 9, pp. 2045-2050, 1995.

[11] V. Yermilov, J. Rubio, and H. Ohshima, "Formation of 8-nitroguanine in DNA treated with peroxynitrite in vitro and its rapid removal from DNA by depurination," FEBS Letters, vol. 376, no. 3, pp. 207-210, 1995.

[12] L. A. Loeb and B. D. Preston, "Mutagenesis by apurinic/ apyrimidinic sites," Annual Review of Genetics, vol. 20, pp. 201-230, 1986.

[13] L. Haracska, I. Unk, R. E. Johnson et al., "Roles of yeast DNA polymerases $\delta$ and $\zeta$ of Rev 1 in the bypass of abasic sites," Genes and Development, vol. 15, no. 8, pp. 945-954, 2001.

[14] X. Wu, K. Takenaka, E. Sonoda et al., "Critical roles for polymerase $\zeta$ in cellular tolerance to nitric oxide-induced DNA damage," Cancer Research, vol. 66, no. 2, pp. 748-754, 2006.

[15] N. Suzuki, M. Yasui, N. E. Geacintov, V. Shafirovich, and S. Shibutani, "Miscoding events during DNA synthesis past the nitration-damaged base 8-nitroguanine," Biochemistry, vol. 44, no. 25, pp. 9238-9245, 2005.

[16] S. Akatsuka and S. Toyokuni, "Genome-scale approaches to investigate oxidative DNA damage," Journal of Clinical Biochemistry and Nutrition, vol. 47, no. 2, pp. 91-97, 2010.

[17] S. Pinlaor, Y. Hiraku, N. Ma et al., "Mechanism of NOmediated oxidative and nitrative DNA damage in hamsters infected with Opisthorchis viverrini: a model of inflammation-mediated carcinogenesis," Nitric Oxide, vol. 11, no. 2, pp. 175-183, 2004.

[18] T. Patel, "Increasing incidence and mortality of primary intrahepatic cholangiocarcinoma in the United States," Hepatology, vol. 33, no. 6, pp. 1353-1357, 2001.

[19] S. Sriamporn, P. Pisani, V. Pipitgool, K. Suwanrungruang, S. Kamsa-ard, and D. H. Parkin, "Prevalence of Opisthorchis viverrini infection and incidence of cholangiocarcinoma in Khon Kaen, Northeast Thailand," Tropical Medicine and International Health, vol. 9, no. 5, pp. 588-594, 2004.

[20] B. Sripa and S. Kaewkes, "Localisation of parasite antigens and inflammatory responses in experimental opisthorchiasis," International Journal for Parasitology, vol. 30, no. 6, pp. 735-740, 2000.

[21] M. Riganti, S. Pungpak, B. Punpoowong, D. Bunnag, and T. Harinasuta, "Human pathology of Opisthorchis viverrini infection: a comparison of adults and children," The Southeast Asian Journal of Tropical Medicine and Public Health, vol. 20, no. 1, pp. 95-100, 1989.

[22] S. Pinlaor, Y. Hiraku, P. Yongvanit et al., "iNOS-dependent DNA damage via NF- $\kappa$ B expression in hamsters infected with Opisthorchis viverrini and its suppression by the antihelminthic drug praziquantel," International Journal of Cancer, vol. 119, no. 5, pp. 1067-1072, 2006.

[23] S. Pinlaor, N. Ma, Y. Hiraku et al., "Repeated infection with Opisthorchis viverrini induces accumulation of 8nitroguanine and 8-oxo-7, 8-dihydro- $2^{\prime}$-deoxyguanine in the bile duct of hamsters via inducible nitric oxide synthase," Carcinogenesis, vol. 25, no. 8, pp. 1535-1542, 2004.

[24] S. Pinlaor, P. Yongvanit, Y. Hiraku et al., "8-nitroguanine formation in the liver of hamsters infected with Opisthorchis viverrini," Biochemical and Biophysical Research Communications, vol. 309, no. 3, pp. 567-571, 2003.

[25] S. Pinlaor, S. Tada-Oikawa, Y. Hiraku et al., "Opisthorchis viverrini antigen induces the expression of Toll-like receptor
2 in macrophage RAW cell line," International Journal for Parasitology, vol. 35, no. 6, pp. 591-596, 2005.

[26] S. Pinlaor, B. Sripa, N. Ma et al., "Nitrative and oxidative DNA damage in intrahepatic cholangiocarcinoma patients in relation to tumor invasion," World Journal of Gastroenterology, vol. 11, no. 30, pp. 4644-4649, 2005.

[27] R. Thanan, M. Murata, S. Pinlaor et al., "Urinary 8-oxo7, 8-dihydro-2'-deoxyguanosine in patients with parasite infection and effect of antiparasitic drug in relation to cholangiocarcinogenesis," Cancer Epidemiology Biomarkers and Prevention, vol. 17, no. 3, pp. 518-524, 2008.

[28] R. M. Peek Jr. and M. J. Blaser, "Helicobacter pylori and gastrointestinal tract adenocarcinomas," Nature Reviews Cancer, vol. 2, no. 1, pp. 28-37, 2002.

[29] O. Handa, Y. Naito, and T. Yoshikawa, "Helicobacter pylori: a ROS-inducing bacterial species in the stomach," Inflammation Research, vol. 59, no. 12, pp. 997-1003, 2010.

[30] S. Maeda, M. Akanuma, Y. Mitsuno et al., "Distinct mechanism of Helicobacter pylori-mediated NF- $\kappa \mathrm{B}$ activation between gastric cancer cells and monocytic cells," Journal of Biological Chemistry, vol. 276, no. 48, pp. 44856-44864, 2001.

[31] E. Pikarsky, R. M. Porat, I. Stein et al., "NF- $\kappa$ B functions as a tumour promoter in inflammation-associated cancer," Nature, vol. 431, no. 7007, pp. 461-466, 2004.

[32] Y. J. Surh, K. S. Chun, H. H. Cha et al., "Molecular mechanisms underlying chemopreventive activities of anti-inflammatory phytochemicals: down-regulation of COX-2 and iNOS through suppression of NF- $\kappa$ B activation," Mutation Research, vol. 480-481, pp. 243-268, 2001.

[33] E. E. Mannick, L. E. Bravo, G. Zarama et al., "Inducible nitric oxide synthase, nitrotyrosine, and apoptosis in Helicobacter pylori gastritis: effect of antibiotics and antioxidants," Cancer Research, vol. 56, no. 14, pp. 3238-3243, 1996.

[34] S. Fu, K. S. Ramanujam, A. Wong et al., "Increased expression and cellular localization of inducible nitric oxide synthase and cyclooxygenase 2 in Helicobacter pylori gastritis," Gastroenterology, vol. 116, no. 6, pp. 1319-1329, 1999.

[35] S. O. Cho, J. W. Lim, K. H. Kim, and H. Kim, "Involvement of ras and AP-1 in Helicobacter pylori-induced expression of COX-2 and iNOS in gastric epithelial AGS cells," Digestive Diseases and Sciences, vol. 55, no. 4, pp. 988-996, 2010.

[36] N. Ma, Y. Adachi, Y. Hiraku et al., "Accumulation of 8nitroguanine in human gastric epithelium induced by Helicobacter pylori infection," Biochemical and Biophysical Research Communications, vol. 319, no. 2, pp. 506-510, 2004.

[37] IARC, "cancer of female reproductive tract," in World Cancer Report, B. W. Stewart and P. Kleihues, Eds., pp. 215-222, IARC Press, Lyon, France, 2003.

[38] Y. Hiraku, T. Tabata, N. Ma, M. Murata, X. Ding, and S. Kawanishi, "Nitrative and oxidative DNA damage in cervical intraepithelial neoplasia associated with human papilloma virus infection," Cancer Science, vol. 98, no. 7, pp. 964-972, 2007.

[39] R. Klaes, T. Friedrich, D. Spitkovsky et al., "Overexpression of p16ink4A as a specific marker for dysplastic and neoplastic epithelial cells of the cervix uteri," International Journal of Cancer, vol. 92, no. 2, pp. 276-284, 2001.

[40] T. Sano, T. Oyama, K. Kashiwabara, T. Fukuda, and T. Nakajima, "Expression status of p16 protein is associated with human papillomavirus oncogenic potential in cervical and genital lesions," American Journal of Pathology, vol. 153, no. 6, pp. 1741-1748, 1998.

[41] M. von Knebel Doeberitz, "New markers for cervical dysplasia to visualise the genomic chaos created by aberrant 
oncogenic papillomavirus infections," European Journal of Cancer, vol. 38, no. 17, pp. 2229-2242, 2002.

[42] J. L. Wang, B. Y. Zheng, X. D. Li, T. Angstrom, M. S. Lindstrom, and K. L. Wallin, "Predictive significance of the alterations of p16INK4A, p14ARF, p53, and proliferating cell nuclear antigen expression in the progression of cervical cancer," Clinical Cancer Research, vol. 10, no. 7, pp. 24072414, 2004.

[43] A. L. McDermott, S. N. Dutt, and J. C. Watkinson, "The aetiology of nasopharyngeal carcinoma," Clinical Otolaryngology and Allied Sciences, vol. 26, no. 2, pp. 82-92, 2001.

[44] H. W. Lo, S. C. Hsu, M. Ali-Seyed et al., "Nuclear interaction of EGFR and STAT3 in the activation of the iNOS/NO pathway," Cancer Cell, vol. 7, no. 6, pp. 575-589, 2005.

[45] E. Tedeschi, M. Menegazzi, D. Margotto, H. Suzuki, U. Forstermann, and H. Kleinert, "Anti-inflammatory actions of St. John's wort: inhibition of human inducible nitric-oxide synthase expression by down-regulating signal transducer and activator of transcription- $1 \alpha$ (STAT- $1 \alpha$ ) activation," Journal of Pharmacology and Experimental Therapeutics, vol. 307, no. 1, pp. 254-261, 2003.

[46] H. Chen, L. Hutt-Fletcher, L. Cao, and S. D. Hayward, "A positive autoregulatory loop of LMP1 expression and STAT activation in epithelial cells latently infected with EpsteinBarr virus," Journal of Virology, vol. 77, no. 7, pp. 4139-4148, 2003.

[47] Y. Tao, X. Song, X. Deng et al., "Nuclear accumulation of epidermal growth factor receptor and acceleration of G1/S stage by Epstein-Barr-encoded oncoprotein latent membrane protein 1," Experimental Cell Research, vol. 303, no. 2, pp. 240-251, 2005.

[48] J. S. Yu, H. C. Tsai, C. C. Wu et al., "Induction of inducible nitric oxide synthase by Epstein-Barr virus B95-8-derived LMP1 in Balb/3T3 cells promotes stress-induced cell death and impairs LMP1-mediated transformation," Oncogene, vol. 21, no. 52, pp. 8047-8061, 2002.

[49] Y. J. Huang, B. B. Zhang, N. Ma, M. Murata, A. Z. Tang, and G. W. Huang, "Nitrative and oxidative DNA damage as potential survival biomarkers for nasopharyngeal carcinoma," Medical Oncology, vol. 28, no. 1, pp. 377-384, 2011.

[50] N. Ma, M. Kawanishi, Y. Hiraku et al., "Reactive nitrogen species-dependent DNA damage in EBV-associated nasopharyngeal carcinoma: the relation to STAT3 activation and EGFR expression," International Journal of Cancer, vol. 122, no. 11, pp. 2517-2525, 2008.

[51] T. Poynard, M. F. Yuen, V. Ratziu, and C. L. Lai, "Viral hepatitis C," The Lancet, vol. 362, no. 9401, pp. 2095-2100, 2003.

[52] B. Bressac, M. Kew, J. Wands, and M. Ozturk, "Selective G to $\mathrm{T}$ mutations of $\mathrm{p} 53$ gene in hepatocellular carcinoma from southern Africa," Nature, vol. 350, no. 6317, pp. 429-431, 1991.

[53] W. H. Caselmann and M. Alt, "Hepatitis C virus infection as a major risk factor for hepatocellular carcinoma," Journal of Hepatology, vol. 24, no. 2, supplement, pp. 61-66, 1996.

[54] I. C. Hsu, R. A. Metcalf, T. Sun, J. A. Welsh, N. J. Wang, and C. C. Harris, "Mutational hotspot in the p53 gene in human hepatocellular carcinomas," Nature, vol. 350, no. 6317, pp. 427-428, 1991.

[55] T. Oda, H. Tsuda, A. Scarpa, M. Sakamoto, and S. Hirohashi, "p53 gene mutation spectrum in hepatocellular carcinoma," Cancer Research, vol. 52, no. 22, pp. 6358-6364, 1992.
[56] S. Horiike, S. Kawanishi, M. Kaito et al., "Accumulation of 8-nitroguanine in the liver of patients with chronic hepatitis C," Journal of Hepatology, vol. 43, no. 3, pp. 403-410, 2005.

[57] N. Fujita, S. Horiike, R. Sugimoto et al., "Hepatic oxidative DNA damage correlates with iron overload in chronic hepatitis C patients," Free Radical Biology and Medicine, vol. 42, no. 3, pp. 353-362, 2007.

[58] H. Tanaka, N. Fujita, R. Sugimoto et al., "Hepatic oxidative DNA damage is associated with increased risk for hepatocellular carcinoma in chronic hepatitis C," British Journal of Cancer, vol. 98, no. 3, pp. 580-586, 2008.

[59] N. Fujita, R. Sugimoto, N. Ma et al., "Comparison of hepatic oxidative DNA damage in patients with chronic hepatitis B and C," Journal of Viral Hepatitis, vol. 15, no. 7, pp. 498-507, 2008.

[60] N. Ma, R. Thanan, H. Kobayashi et al., "Nitrative DNA damage and Oct3/4 expression in urinary bladder cancer with Schistosoma haematobium infection," Biochemical and Biophysical Research Communications, vol. 414, no. 2, pp. 344-349, 2011.

[61] Y. Hiraku, S. Kawanishi, T. Ichinose, and M. Murata, "The role of iNOS-mediated DNA damage in infection- and asbestos-induced carcinogenesis," Annals of the New York Academy of Sciences, vol. 1203, pp. 15-22, 2010.

[62] P. Chaiyarit, N. Ma, Y. Hiraku et al., "Nitrative and oxidative DNA damage in oral lichen planus in relation to human oral carcinogenesis," Cancer Science, vol. 96, no. 9, pp. 553-559, 2005.

[63] X. Ding, Y. Hiraku, N. Ma et al., "Inducible nitric oxide synthase-dependent DNA damage in mouse model of inflammatory bowel disease," Cancer Science, vol. 96, no. 3, pp. 157-163, 2005.

[64] Y. Hoki, Y. Hiraku, N. Ma et al., "iNOS-dependent DNA damage in patients with malignant fibrous histiocytoma in relation to prognosis," Cancer Science, vol. 98, no. 2, pp. 163168, 2007.

[65] Y. Hoki, M. Murata, Y. Hiraku et al., "8-nitroguanine as a potential biomarker for progression of malignant fibrous histiocytoma, a model of inflammation-related cancer," Oncology Reports, vol. 18, no. 5, pp. 1165-1169, 2007.

[66] R. P. Schins, "Mechanisms of genotoxicity of particles and fibers," Inhalation Toxicology, vol. 14, no. 1, pp. 57-78, 2002.

[67] IARC, "Asbestos," IRAC Mongraphs on the Evalution of Carcinogenic Risk to Humans, vol. 7, supplement 1, pp. 106-116, 1987.

[68] J. E. Craighead, J. L. Abraham, A. Churg et al., "The pathology of asbestos-associated diseases of the lungs and pleural cavities: diagnostic criteria and proposed grading schema. Report of the pneumoconiosis committee of the college of American pathologists and the national institute for occupational safety and health," Archives of Pathology and Laboratory Medicine, vol. 106, no. 11, pp. 544-596, 1982.

[69] C. B. Manning, V. Vallyathan, and B. T. Mossman, "Diseases caused by asbestos: mechanisms of injury and disease development," International Immunopharmacology, vol. 2, no. 2-3, pp. 191-200, 2002.

[70] J. P. Eiserich, M. Hristova, C. E. Cross et al., "Formation of nitric oxide-derived inflammatory oxidants by myeloperoxidase in neutrophils," Nature, vol. 391, no. 6665, pp. 393-397, 1998.

[71] J. P. Gaut, J. Byun, H. D. Tran et al., "Myeloperoxidase produces nitrating oxidants in vivo," Journal of Clinical Investigation, vol. 109, no. 10, pp. 1311-1319, 2002. 
[72] S. Tanaka, N. Choe, D. R. Hemenway, S. Zhu, S. Matalon, and E. Kagan, "Asbestos inhalation induces reactive nitrogen species and nitrotyrosine formation in the lungs and pleura of the rat," Journal of Clinical Investigation, vol. 102, no. 2, pp. 445-454, 1998.

[73] A. van der Vliet, J. P. Eiserich, M. K. Shigenaga, and C. E. Cross, "Reactive nitrogen species and tyrosine nitration in the respiratory tract: epiphenomena or a pathobiologic mechanism of disease?" American Journal of Respiratory and Critical Care Medicine, vol. 160, no. 1, pp. 1-9, 1999.

[74] A. Haegens, A. van der Vliet, K. J. Butnor et al., "Asbestosinduced lung inflammation and epithelial cell proliferation are altered in myeloperoxidase-null mice," Cancer Research, vol. 65, no. 21, pp. 9670-9677, 2005.

[75] A. Ekbom, C. Helmick, M. Zack, and H. O. Adami, "Increased risk of large-bowel cancer in Crohn's disease with colonic involvement," The Lancet, vol. 336, no. 8711, pp. 357-359, 1990.

[76] L. J. Hofseth, S. Saito, S. P. Hussain et al., "Nitric oxideinduced cellular stress and p53 activation in chronic inflammation," Proceedings of the National Academy of Sciences of the United States of America, vol. 100, no. 1, pp. 143-148, 2003.

[77] I. I. Singer, D. W. Kawka, S. Scott et al., "Expression of inducible nitric oxide synthase and nitrotyrosine in colonic epithelium in inflammatory bowel disease," Gastroenterology, vol. 111, no. 4, pp. 871-885, 1996.

[78] H. Wiseman and B. Halliwell, "Damage to DNA by reactive oxygen and nitrogen species: role in inflammatory disease and progression to cancer," Biochemical Journal, vol. 313, part 1, pp. 17-29, 1996.

[79] C. Scully, M. Beyli, M. C. Ferreiro et al., "Update on oral lichen planus: etiopathogenesis and management," Critical Reviews in Oral Biology and Medicine, vol. 9, no. 1, pp. 86$122,1998$.

[80] M. D. Mignogna, S. Fedele, L. Lo Russo, L. Lo Muzio, and E. Bucci, "Immune activation and chronic inflammation as the cause of malignancy in oral lichen planus: is there any evidence?” Oral Oncology, vol. 40, no. 2, pp. 120-130, 2004.

[81] B. W. Neville and T. A. Day, "Oral cancer and precancerous lesions," CA: A Cancer Journal for Clinicians, vol. 52, no. 4, pp. 195-215, 2002.

[82] J. Reibel, "Prognosis of oral pre-malignant lesions: significance of clinical, histopathological, and molecular biological characteristics," Critical Reviews in Oral Biology \& Medicine, vol. 14, no. 1, pp. 47-62, 2003.

[83] N. Ma, T. Tagawa, Y. Hiraku, M. Murata, X. Ding, and S. Kawanishi, "8-nitroguanine formation in oral leukoplakia, a premalignant lesion," Nitric Oxide, vol. 14, no. 2, pp. 137143, 2006.

[84] J. J. Lee, M. Y. Kuo, S. J. Cheng et al., "Higher expressions of p53 and proliferating cell nuclear antigen (PCNA) in atrophic oral lichen planus and patients with areca quid chewing," Oral Surgery, Oral Medicine, Oral Pathology, Oral Radiology and Endodontology, vol. 99, no. 4, pp. 471-478, 2005.

[85] A. Jemal, R. C. Tiwari, T. Murray et al., "Cancer Statistics, 2004," CA: A Cancer Journal for Clinicians, vol. 54, no. 1, pp. 8-29, 2004.

[86] S. W. Weiss and F. M. Enzinger, "Malignant fibrous histiocytoma. An analysis of 200 cases," Cancer, vol. 41, no. 6, pp. 2250-2266, 1978.

[87] A. Belal, A. Kandil, A. Allam et al., "Malignant fibrous histiocytoma: a retrospective study of 109 cases," American Journal of Clinical Oncology, vol. 25, no. 1, pp. 16-22, 2002.
[88] R. L. Randall, K. H. Albritton, B. J. Ferney, and L. Layfield, "Malignant fibrous histiocytoma of soft tissue: an abandoned diagnosis," The American Journal of Orthopedics, vol. 33, no. 12, pp. 602-608, 2004.

[89] M. F. Melhem, A. I. Meisler, R. Saito, G. G. Finley, H. R. Hockman, and R. A. Koski, "Cytokines in inflammatory malignant fibrous histiocytoma presenting with leukemoid reaction," Blood, vol. 82, no. 7, pp. 2038-2044, 1993.

[90] K. K. Richter, D. M. Parham, J. Scheele, R. Hinze, and F. W. Rath, "Presarcomatous lesions of experimentally induced sarcomas in rats: morphologic, histochemical, and immunohistochemical features," In Vivo, vol. 13, no. 4, pp. 349-355, 1999.

[91] F. Michor, Y. Iwasa, B. Vogelstein, C. Lengauer, and M. A. Nowak, "Can chromosomal instability initiate tumorigenesis?" Seminars in Cancer Biology, vol. 15, no. 1, pp. 43-49, 2005.

[92] N. P. Degtyareva, L. Chen, P. Mieczkowski, T. D. Petes, and P. W. Doetsch, "Chronic oxidative DNA damage due to DNA repair defects causes chromosomal instability in Saccharomyces cerevisiae," Molecular and Cellular Biology, vol. 28, no. 17, pp. 5432-5445, 2008.

[93] B. Trouiller, R. Reliene, A. Westbrook, P. Solaimani, and R. H. Schiestl, "Titanium dioxide nanoparticles induce DNA damage and genetic instability in vivo in mice," Cancer Research, vol. 69, no. 22, pp. 8784-8789, 2009.

[94] K. Mazan-Mamczarz, P. R. Hagner, Y. Zhang et al., "ATM regulates a DNA damage response posttranscriptional RNA operon in lymphocytes," Blood, vol. 117, no. 8, pp. 24412450, 2011.

[95] E. M. Goetz, B. Shankar, Y. Zou et al., "ATM-dependent IGF-1 induction regulates secretory clusterin expression after DNA damage and in genetic instability," Oncogene, vol. 30, no. 35, pp. 3745-3754, 2011.

[96] R. Medeiros, R. D. Prediger, G. F. Passos et al., "Connecting TNF- $\alpha$ signaling pathways to iNOS expression in a mouse model of Alzheimer's disease: relevance for the behavioral and synaptic deficits induced by amyloid $\beta$ protein," Journal of Neuroscience, vol. 27, no. 20, pp. 5394-5404, 2007.

[97] J. Nandi, B. Saud, J. M. Zinkievich, Z. J. Yang, and R. A. Levine, "TNF- $\alpha$ modulates iNOS expression in an experimental rat model of indomethacin-induced jejunoileitis," Molecular and Cellular Biochemistry, vol. 336, no. 1-2, pp. 1724, 2009.

[98] M. Natarajan, C. F. Gibbons, S. Mohan, S. Moore, and M. A. Kadhim, "Oxidative stress signalling: a potential mediator of tumour necrosis factor $\alpha$-induced genomic instability in primary vascular endothelial cells," British Journal of Radiology, vol. 80, supplement 1, pp. S13-S22, 2007.

[99] B. Yan, Y. Peng, and C. Y. Li, "Molecular analysis of genetic instability caused by chronic inflammation," Methods in Molecular Biology, vol. 512, pp. 15-28, 2009.

[100] I. M. Adcock, L. Tsaprouni, P. Bhavsar, and K. Ito, "Epigenetic regulation of airway inflammation," Current Opinion in Immunology, vol. 19, no. 6, pp. 694-700, 2007.

[101] F. Armenante, M. Merola, A. Furia, and M. Palmieri, "Repression of the IL-6 gene is associated with hypermethylation," Biochemical and Biophysical Research Communications, vol. 258, no. 3, pp. 644-647, 1999.

[102] S. Garaud, C. Le Dantec, S. Jousse-Joulin et al., "IL-6 Modulates CD5 expression in B cells from patients with lupus by regulating DNA methylation," Journal of Immunology, vol. 182, no. 9, pp. 5623-5632, 2009. 
[103] H. Isomoto, J. L. Mott, S. Kobayashi et al., "Sustained IL-6/STAT-3 signaling in cholangiocarcinoma cells due to SOCS-3 epigenetic silencing," Gastroenterology, vol. 132, no. 1, pp. 384-396, 2007.

[104] R. Thaler, M. Agsten, S. Spitzer et al., "Homocysteine suppresses the expression of the collagen cross-linker lysyl oxidase involving IL-6, Fli1, and epigenetic DNA methylation," Journal of Biological Chemistry, vol. 286, no. 7, pp. 55785588, 2010.

[105] K. F. To, M. W. Chan, W. K. Leung et al., "Constitutional activation of IL-6-mediated JAK/STAT pathway through hypermethylation of SOCS-1 in human gastric cancer cell line," British Journal of Cancer, vol. 91, no. 7, pp. 1335-1341, 2004.

[106] H. H. Niller, H. Wolf, and J. Minarovits, "Epigenetic dysregulation of the host cell genome in Epstein-Barr virusassociated neoplasia," Seminars in Cancer Biology, vol. 19, no. 3, pp. 158-164, 2009.

[107] F. Chen, Y. Mo, H. Ding et al., "Frequent epigenetic inactivation of Myocardin in human nasopharyngeal carcinoma," Head and Neck, vol. 33, no. 1, pp. 54-59, 2011.

[108] C. Du, T. Huang, D. Sun et al., "CDH4 as a novel putative tumor suppressor gene epigenetically silenced by promoter hypermethylation in nasopharyngeal carcinoma," Cancer Letters, vol. 309, no. 1, pp. 54-61, 2011.

[109] S. Wang, X. Xiao, X. Zhou et al., "TFPI-2 is a putative tumor suppressor gene frequently inactivated by promoter hypermethylation in nasopharyngeal carcinoma," BMC Cancer, vol. 10, article 617, 2010.

[110] Z. Zhang, D. Sun, N. Van Do, A. Tang, L. Hu, and G. Huang, "Inactivation of RASSF2A by promoter methylation correlates with lymph node metastasis in nasopharyngeal carcinoma," International Journal of Cancer, vol. 120, no. 1, pp. 32-38, 2007.

[111] D. Rossetto, A. W. Truman, S. J. Kron, and J. Cote, "Epigenetic modifications in double-strand break DNA damage signaling and repair," Clinical Cancer Research, vol. 16, no. 18 , pp. 4543-4552, 2010.

[112] T. Sawa and H. Ohshima, "Nitrative DNA damage in inflammation and its possible role in carcinogenesis," Nitric Oxide, vol. 14, no. 2, pp. 91-100, 2006.

[113] F. Colotta, P. Allavena, A. Sica, C. Garlanda, and A. Mantovani, "Cancer-related inflammation, the seventh hallmark of cancer: links to genetic instability," Carcinogenesis, vol. 30, no. 7, pp. 1073-1081, 2009.

[114] G. P. Pfeifer and A. Besaratinia, "Mutational spectra of human cancer," Human Genetics, vol. 125, no. 5-6, pp. 493-506, 2009. 

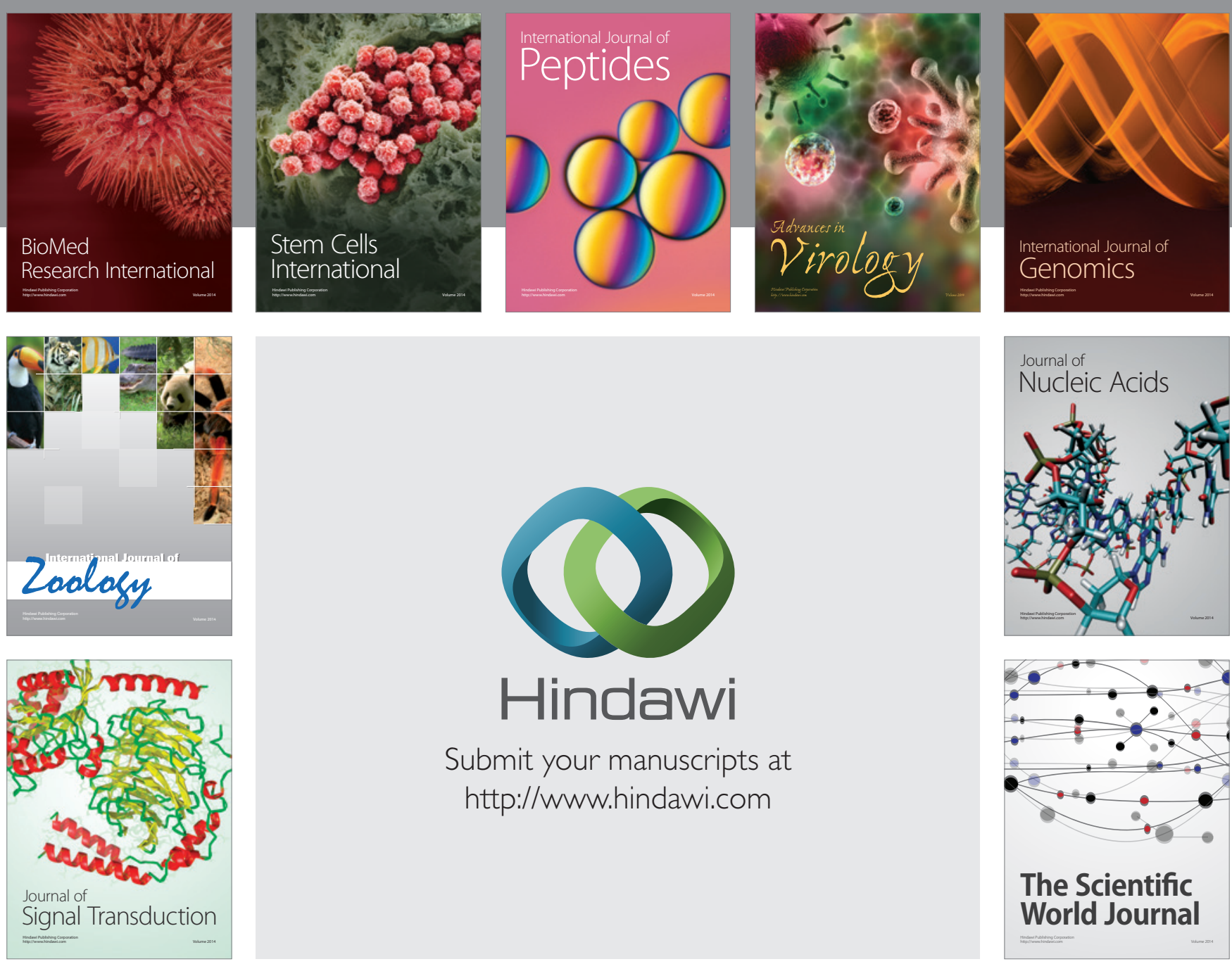

Submit your manuscripts at

http://www.hindawi.com
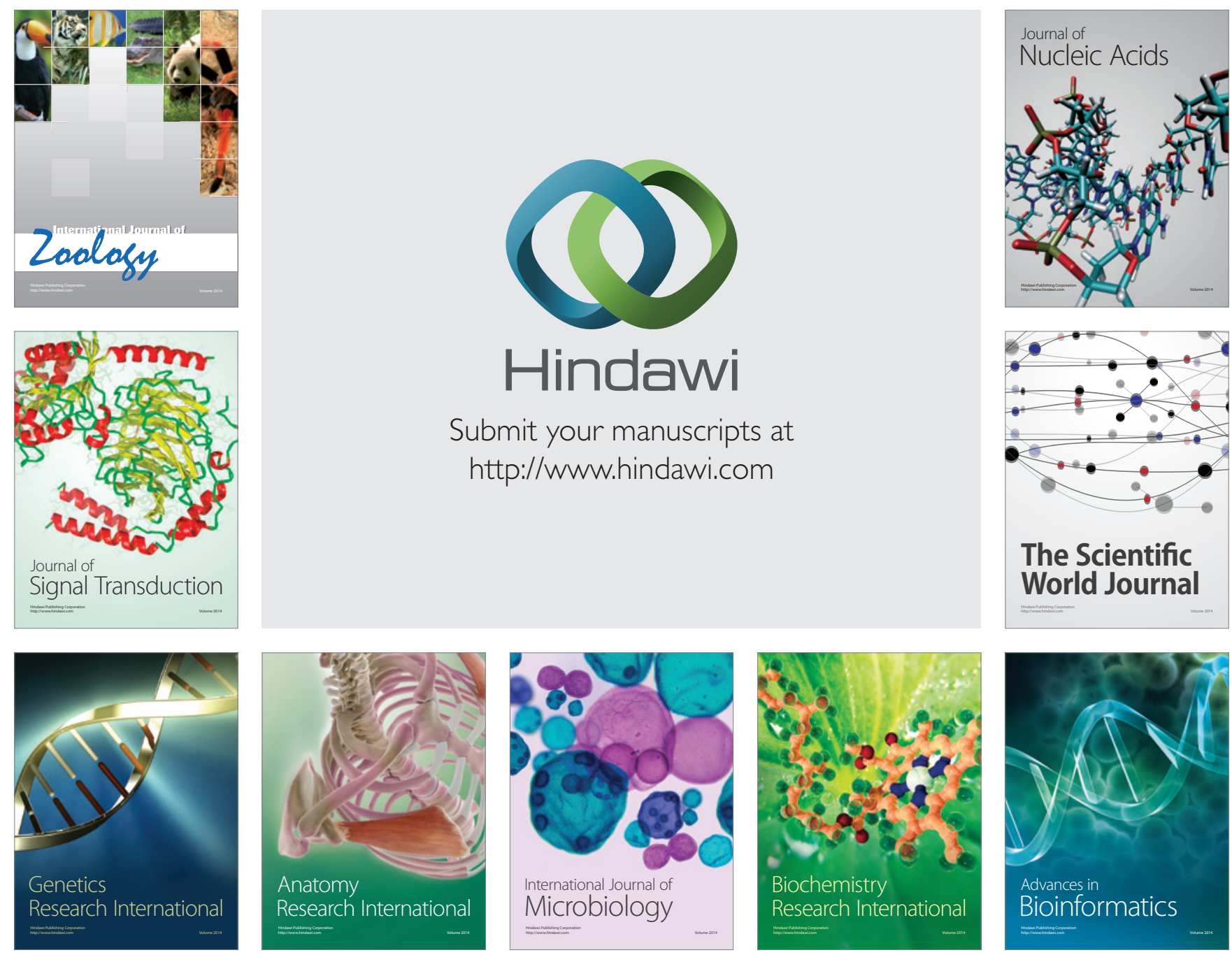

The Scientific World Journal
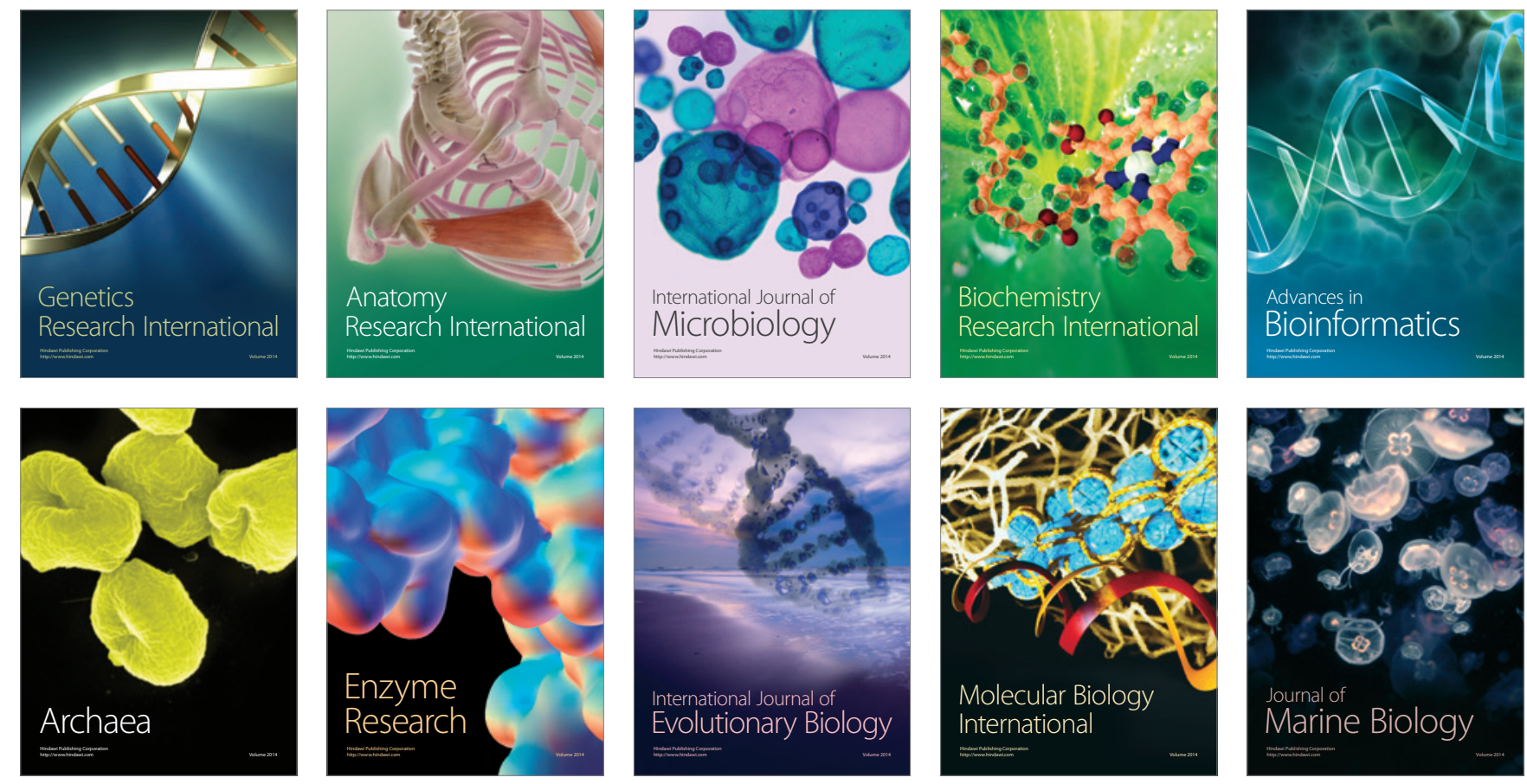